\title{
Factors Affecting Chinese Young Adults' Acceptance of Connected Health
}

\author{
Lin Jia ${ }^{1,2, *}$, Yuting Tan ${ }^{1}$, Feiyu Han ${ }^{1}$, Yi Zhou ${ }^{1}$, Chu Zhang ${ }^{1}$ and Yufei Zhang ${ }^{1}$ \\ 1 School of Management and Economics, Beijing Institute of Technology, Beijing 100081, China; \\ tanyuting626sy@163.com (Y.T.); Ashley_hanf@163.com (F.H.); 1120162855@bit.edu.cn (Y.Z.); \\ 1120162822@bit.edu.cn (C.Z.); 1120162882@bit.edu.cn (Y.Z.) \\ 2 Sustainable Development Research Institute for Economy and Society of Beijing, Beijing 100081, China \\ * Correspondence: jialin87@bit.edu.cn; Tel.: +86-010-6891-8401
}

Received: 5 March 2019; Accepted: 16 April 2019; Published: 22 April 2019

check for updates

\begin{abstract}
The global health care industry faces several challenges, such as an aging population, insufficient medical resources, and uneven allocation of high-quality medical resources. These challenges impede the development of a sustainable medical care system. Connected health aims to relieve these challenges by deploying information technology in healthcare. However, there is a lack of research on adoption of connected health and as a result, its acceptance rate is still low. This study summarized 25 potential factors that may affect its acceptance, and ranked their importance by performing a best-worst scaling experiment. Fifteen important factors were distinguished, which included nine technological factors, five individual factors, and one environmental factor. To explore how these factors affect individuals' acceptance of connected health, this study conducted a qualitative study based on grounded theory. We coded the contents collected in a semi-structural interview by applying open coding, axial coding, and selective coding techniques. Finally, nine core categories were distinguished, and a conceptual model was proposed to explain how these core categories affect individuals' acceptance of connected health. This study deepens our understanding of factors affecting the acceptance of connected health and helps build a sustainable medical care system.
\end{abstract}

Keywords: connected health; sustainable medical care system; adoption; best-worst scaling method; grounded theory

\section{Introduction}

Health care is a topic closely related to the public interest and the sustainability of our society, and thereafter has always been a matter of concern. Nowadays, the global health care industry faces many challenges, such as an aging population, a higher rate of chronic diseases, and rejuvenation of chronic disease patients [1]. These challenges increase the burden of our medical systems. However, the overall medical resources are insufficient [2] and their allocation is uneven because of disproportionate development [3]. This extends patients' waiting time, increases the workloads of physicians, and enhances medical expenditures [4]. Healthcare organizations started to consider how to apply information technology (IT) in the health care system to improve its automation level and efficiency [5]. Proper use of IT in the health care system will improve our ability to collect, store, handle, analyze and transmit medical data in a secure and efficient manner, and help relieve current challenges [6,7]. With this in mind, many countries released their new health care systems. For example, the department of health in the UK launched "telemedicine", a national service framework for the elderly. It is a comprehensive sociotechnical model for medical service delivery with the help of software solutions [4]. "Telemedicine" is also the prototype of connected health, which aims to "bring the right information to the right person at the right time" [7]. 
Connected health can bring benefits for patients, medical organizations, and society. For patients, it allows them to remotely access medical organizations and thereafter provides convenience and flexibility for patients. Additionally, it provides patients with timely health conditions and contributes to disease prevention [6]. Moreover, patients can authorize medical institutions to share their information with other organizations to customize services they need. For medical organizations, connected health will change the approach of patient management and disease prevention and help develop a more effective and efficient medical system through pervasive computing technologies [8]. For society, connected health facilitates promotes the coordination among different stakeholders of medical systems and fosters the achievement of sustainability [5].

There exists an optimistic forecast for the development of connected health. For example, Allaert et al. [8] predicted that connected health would face a rapid development and reap a reward of several billion euro in the coming years. However, individuals' acceptance of connected health is still low. According to a public survey conducted in the U.S. and Canada, only 8.9\% to $18.2 \%$ of individuals are familiar with connected health, and most people are not aware of it. Meanwhile, people do not understand what connected health can bring to our medical industry, and other stakeholders in the health care system do not understand citizens' opinions and needs towards connected health [4]. More studies are needed to explore factors affecting individuals' acceptance of connected health to facilitate user involvement and expand the use of connected health [9].

Past literature on connected health mainly concentrates on its possibility from the perspective of technology. For example, Rose [10] summarized technologies that can be used in the connected health system and described the challenges to apply those technologies in connected health. Skiba [11] investigated the state-of-the-art technologies relevant to connected health and analyzed their potential in supporting connected health. However, technology is not the whole story although it serves as the infrastructure of the connected health system. There are factors other than technology that will affect the success of connected health. For example, both the Food and Drug Administration (FDA) and the Agency for Healthcare Research and Quality in the U.S.A have requested more attention be made to human factors when designing medical devices and systems [12].

To bridge the gap mentioned above, this study adopted the technology-organization-environment (TOE) framework and explored factors affecting individuals' acceptance of connected health. This study has three research questions: first, what are potential factors that will affect individuals' acceptance of connected health; second, what is the ranking of their importance; and third, how do these factors affect individuals' acceptance of connected health. Specifically, this study summarized 25 potential factors by performing a thorough literature review and a group discussion with 27 undergraduate students. The factors were categorized into technology, individuals, and environmental factors. Then, the study relied on the balanced incomplete block design (BIBD) algorithm to design a best-worst scaling instrument to collect data and rank the importance of factors based on their average B-W scores. In addition, a semi-structured interview was performed to collect text contents and a qualitative study based on grounded theory was conducted to explore how different factors affect individuals' intention to use connected health services. Conclusions were also discussed.

\section{Literature Review}

\subsection{What is Connected Health?}

In 2001, the Department of Health in the UK released the "National Service Framework for Older People", and the key tenet was telemedicine. Telemedicine has been defined as "the use of health informatics, disease management, and home telehealth technologies to enhance and extend care and case management to facilitate access to care and improve the health of designated individuals and populations with the specific intent of providing the right care in the right place at the right time" (p. 3) [13]. However, there was limited evidence of the effectiveness and efficiency of telemedicine at 
that time [14]. Although there was no evidence at that time, the Department of Health in the UK still views telemedicine as an approach to tackle healthcare challenges.

Recently, connected health was proposed as a relatively new lexicon for telemedicine. It is an evolution of telemedicine with a particular focus on patients with chronic diseases, and is believed to have great potential in alleviating the healthcare challenges our medical systems face today [1,4]. Connected health is relatively new, and there is no consensus on its definition. Table 1 summarizes some definitions from past literature. The original purpose of connected health was to help health professionals remotely monitor patients with chronic medical conditions, especially the elderly and inexperienced technology users, with home medical devices. It aims to promote self-management and self-care of disease [1]. For example, patients with hypertension can use a blood pressure monitor to track their blood pressure at home, and the results will be automatically sent to a health professional via the Internet [4]. As the popularization of mobile devices such as smartphones and wearable devices has increased, they have been incorporated into a new mode of the medical care system, named mobile health (mHealth) [10]. It broadens the connotation of telemedicine and connected health.

Table 1. Definitions of connected health.

O'Neill et al. [15] defined connected health as "technology aiming to provide healthcare remotely by assessing health, wellbeing and other parameters in the home whilst at the same time being connected with health care professionals through internet or phone connections" (p. 151).

Caulfield and Donnelly [16] defined that connected health "encompasses terms such as wireless, digital, electronic, mobile, and tele-health and refers to a conceptual model for health management where devices, services or interventions are designed around the patient's needs, and health related data is shared, in such a way that the patient can receive care in the most proactive and efficient manner possible. All stakeholders in the process are 'connected' by means of timely sharing and presentation of accurate and pertinent information regarding patient status through smarter use of data, devices, communication platforms and people" (p. 705).

Barr et al. [4] described connected health as "a way of connecting a person with a long term-illness, for example, high blood pressure, diabetes or asthma, from their own home to the health professional (doctor, pharmacist or nurse) looking after them" (p. 249).

Chouvarda et al. [6] defined connected health as a mode which "aims for the optimal access, sharing, analysis and use of health data via systematic application of healthcare information technology, in other words to 'offer the correct information to the correct person at the correct time', so that health actors (citizens, patients, clinicians, policy makers) make better decisions for health and care" (p. 23).

All modes of medical care systems mentioned above focus on the information and medical service delivery between hospitals and patients. However, healthcare is a complex process composed of many stakeholders other than patients and hospitals [17]. In addition, patients' health parameters, such as hemogram index, are just normal indicators reflecting their health conditions. Their health conditions are also affected by other factors, such as pollution index, gym activities, emotion status, and dietary habits [6]. As medical care expenditure quickly increases, professionals need more parameters outside the limit, and we should consider how to combine information from different sources and improve the value of every dollar we spend on patients. Connected health should not only be limited to remote connection between patients and hospitals, but also connect information, people, medical facility, medical products, and services of the whole medical industry [1].

This study defines connected health as a patient-centered medical care system that collects all kinds of data relevant to patients with the help of modern technologies (e.g., software, hardware, and wearable devices), connects stakeholders in the medical care industry through timely information sharing, and analyzes integrated data to provide preventive and long-term monitoring medical services and offer a whole picture of the health condition for patients. Connected health helps realize a paradigm shift in health care that is characterized by making preventive, preemptive, and predictive healthcare decisions in a pervasive, participatory, and personalized manner [17]. 


\subsection{Potential Factors Affecting Connected Health Acceptance}

This study introduces two extra dimensions other than technology factors, which are individual factors and environmental factors, by adopting the technology-organization-environment (TOE) framework. The TOE framework, proposed by Tornatzky and Fleisher in 1990 [18], is widely used in research on the acceptance of IT artifacts. It emphasizes the impact of technology characteristics, organizational factors, and external environmental factors on adoption of IT artifacts. Technology factors refer to characteristics of focal technology that will affect its acceptance; organizational factors refer to characteristics of an organization that has the potential to affect the acceptance of focal technology; and environmental factors refer to the macro-environment in which the organization makes acceptance decisions. This study focuses on individuals' acceptance of connected health, and we focus on individual factors but not organizational factors. We summarize factors affecting individuals' acceptance of connected health based on the TOE framework.

\subsubsection{Technology Factors}

Accenture report summarized three categories of technology factors that would affect the acceptance of connected health, which are digital infrastructure, controlled exchange of information, and data analysis [3]. Wearable devices are also anticipated as promising technology infrastructure in the period of Internet of things [9]. Connected health relies on digital devices, especially wearable devices, to collect personal data. There are several factors about wearable devices that may affect individuals' acceptance of connected health. The first variable is device cost. Digital devices, such as wearable devices, are becoming more and more affordable, and this facilitates the popularization of connected health [3]. The second variable is device safety. Devices and systems used in the healthcare industry cannot bring damage to patients [19]. In addition, human factors are important concerns in the design of wearable devices [19]. Specifically, wearable devices should require a high level of ease of use and aesthetic to improve users' experience of using the devices [20,21]. The second category of technology factors is information exchange. It mainly includes two factors. One is device accuracy, referring to the reliability of the connected health devices to test and send information. The other is data security, which requires that healthcare devices should guarantee the confidentiality and privacy of data. The third category of technology factors is data analysis. Collected data is meaningless without reliable analytics. Connected health should incorporate intelligent processing of collected information with professional knowledge to obtain insights [6]. Meanwhile, patients should receive active feedback either from medical professionals or directly from devices with suggestions on preventive, preemptive, and predictive healthcare decisions [6]. In addition, perceived benefits of connected health help facilitate individuals' adoption of connected health [22]. For example, individuals prefer a mode that can help reduce their healthcare expenditures [23].

\subsubsection{Individual Factors}

When it comes to health care systems, it is not a matter of pure technology. Connected health aims to provide customized medical services for patients in an effective and efficient manner. Connected health requires us to be more human factor-oriented when we design a new medical system [15]. Connected health requires users to share information with other organizations in the healthcare industry when necessary, and thereafter individuals' trust in connected health and privacy concern will greatly affect their acceptance of connected health. Past literature discusses the importance of trust and privacy concerns in affecting individuals' acceptance of new modes of healthcare delivery. For example, Katz \& Rice [24] and Barr et al. [4] found that people who have a higher level of trust are more interested in using new healthcare modes, while their privacy concern is a strong inhibitor of information provision in general $[8,25,26]$. 


\subsubsection{Environmental Factors}

Individuals will be affected by opinion of important others, which refers to social influence. When it comes to the health care context, health care professionals should serve as a hub for connected health provisions and convince their patients to use connected health $[1,4,27]$. In addition, individuals are more likely to use connected health if they are familiar with it [28]. Popularity means that there are many others who are using connected health. Individuals will have more chances to get familiar with connected health if it is popular. Moreover, government policy serves as an important signal to cue stakeholders that the governments supports the development of connected health. Burch et al. [22] also mentioned that the enactment of legislation will help promote the further acceptance of connected health across the whole medical industry.

\section{Further Development of the Factor List}

This study performed a review of relevant literature and summarized some factors affecting individuals' acceptance of connected health. However, past literature paid much attention to technology factors while neglecting human factors. To make the factor list more comprehensive, we invited a group of 27 undergraduates to conduct an in-depth discussion. We introduced the purpose of the discussion, explained the definition of connected health and the TOE framework, and presented some practical examples of connected health from both the U.S. and China. First, this study separated participants into 10 groups with 2-3 students in each group. Then, they discussed factors affecting their acceptance of connected health and listed the three most important factors for each dimension of the TOE framework. Third, we read their results group by group in front of all participants without mentioning which group it was, and asked participants to make comments. After the discussion, we asked all respondents to vote whether each factor we obtained affected their acceptance of connected health. All factors obtained from the literature review appeared in the discussion. Finally, we obtained 25 potential factors that may affect individuals' acceptance of connected health, with 12 technological factors, 8 individual factors, and 5 environmental factors (Table 2).

Table 2. Potential factors affecting individuals' acceptance of connected health.

\begin{tabular}{lll}
\hline \multicolumn{1}{c}{ Factor } & \multicolumn{1}{c}{ Brief Description } & Reference \\
\hline 1. Ease of Use & \multicolumn{1}{c}{ Technology-related (12 factors) } & [20] \\
\hline 2. Device Specifications & $\begin{array}{l}\text { Wearable device technical specifications such as battery, } \\
\text { processor performance, and product weight }\end{array}$ & \\
\hline 3. Health Damage & $\begin{array}{l}\text { Whether wearable devices will lead to health damage. For } \\
\text { example, plastic that may cause allergic reactions }\end{array}$ & [19] \\
\hline 4. Data Security & Whether wearables can guarantee data security & [4] \\
\hline 5. Device Accuracy & Whether device readings are accurate & [4] \\
\hline 6. Analytical Reliability & $\begin{array}{l}\text { Whether data analysis in the process of connected health } \\
\text { is reliable }\end{array}$ & [6] \\
\hline 7. Active Feedback & $\begin{array}{l}\text { Whether connected health can help users comprehensively } \\
\text { monitor their body indices and receive feedback in a }\end{array}$ & [6] \\
\hline
\end{tabular}


Table 2. Cont.

\begin{tabular}{|c|c|c|}
\hline Factor & Brief Description & Reference \\
\hline 8. Cost & $\begin{array}{l}\text { Cost that individuals should pay in order to use connected } \\
\text { health, such as device cost, internet subscription fee, and } \\
\text { service charge }\end{array}$ & [3] \\
\hline 9. Aesthetic & $\begin{array}{l}\text { Whether physical features of wearable devices meet the } \\
\text { public appreciation }\end{array}$ & [20] \\
\hline $\begin{array}{l}\text { 10. Basic Service of } \\
\text { Connected Health }\end{array}$ & $\begin{array}{l}\text { Basic services that connected health can offer, such as blood } \\
\text { glucose monitoring, chronic disease management, and } \\
\text { identification of hidden health risks }\end{array}$ & \\
\hline $\begin{array}{l}\text { 11. Personalized Service } \\
\text { of Connected Health }\end{array}$ & $\begin{array}{l}\text { Personalized and customized medical services that become } \\
\text { feasible with support of connected health }\end{array}$ & \\
\hline $\begin{array}{l}\text { 12. Savings in Medical } \\
\text { Expenditure }\end{array}$ & $\begin{array}{l}\text { Whether connected health will help reduce individuals' } \\
\text { medical expenditure }\end{array}$ & [23] \\
\hline \multicolumn{3}{|c|}{ Individual-related factors (8 factors) } \\
\hline 13. Optimism & $\begin{array}{l}\text { Whether users think connected health will offer people } \\
\text { increased control, flexibility, and efficiency }\end{array}$ & \\
\hline 14. Innovativeness & Whether users want to conquer new technology & \\
\hline 15. Discomfort & Worry about being controlled by connected health & \\
\hline 16. Insecurity & $\begin{array}{l}\text { Worry that connected health can't work as normally } \\
\text { as expected }\end{array}$ & \\
\hline 17. Trust & Whether users trust connected health & {$[4,24]$} \\
\hline 18. Health Concern & The extent to which users are concerned over their health & \\
\hline 19. Privacy Concern & The extent to which users are concerned over privacy & {$[8,25,26]$} \\
\hline 20. Purchasing Power & Individual purchasing power & \\
\hline \multicolumn{3}{|c|}{ Environment-related factors (5 factors) } \\
\hline 21. Social Influence & Influence of importance, such as doctors' advice & {$[1,4,27]$} \\
\hline 22. Government Policy & $\begin{array}{l}\text { Whether the government implements policies to facilitate } \\
\text { the development of connected health }\end{array}$ & [22] \\
\hline $\begin{array}{l}\text { 23. Institutional } \\
\text { architecture }\end{array}$ & $\begin{array}{l}\text { Whether there is legislation and technological architecture } \\
\text { that can guarantee user concerns, such as data security }\end{array}$ & \\
\hline 24. Negative Events & $\begin{array}{l}\text { Negative events that are closely related to user concerns, } \\
\text { such as data leakage events }\end{array}$ & \\
\hline 25. Popularity & Popularity of connected health & [28] \\
\hline
\end{tabular}

In the following sections, we performed a mixed method study to explore our research questions. To answer the first two questions, we performed a best-worst scaling experiment to rank the importance of factors. To answer the third question, we conducted a semi-structured interview and performed a qualitative study based on grounded theory to explore how different factors affect individuals' acceptance of connected health. Figure 1 indicates the logic of the current study. 


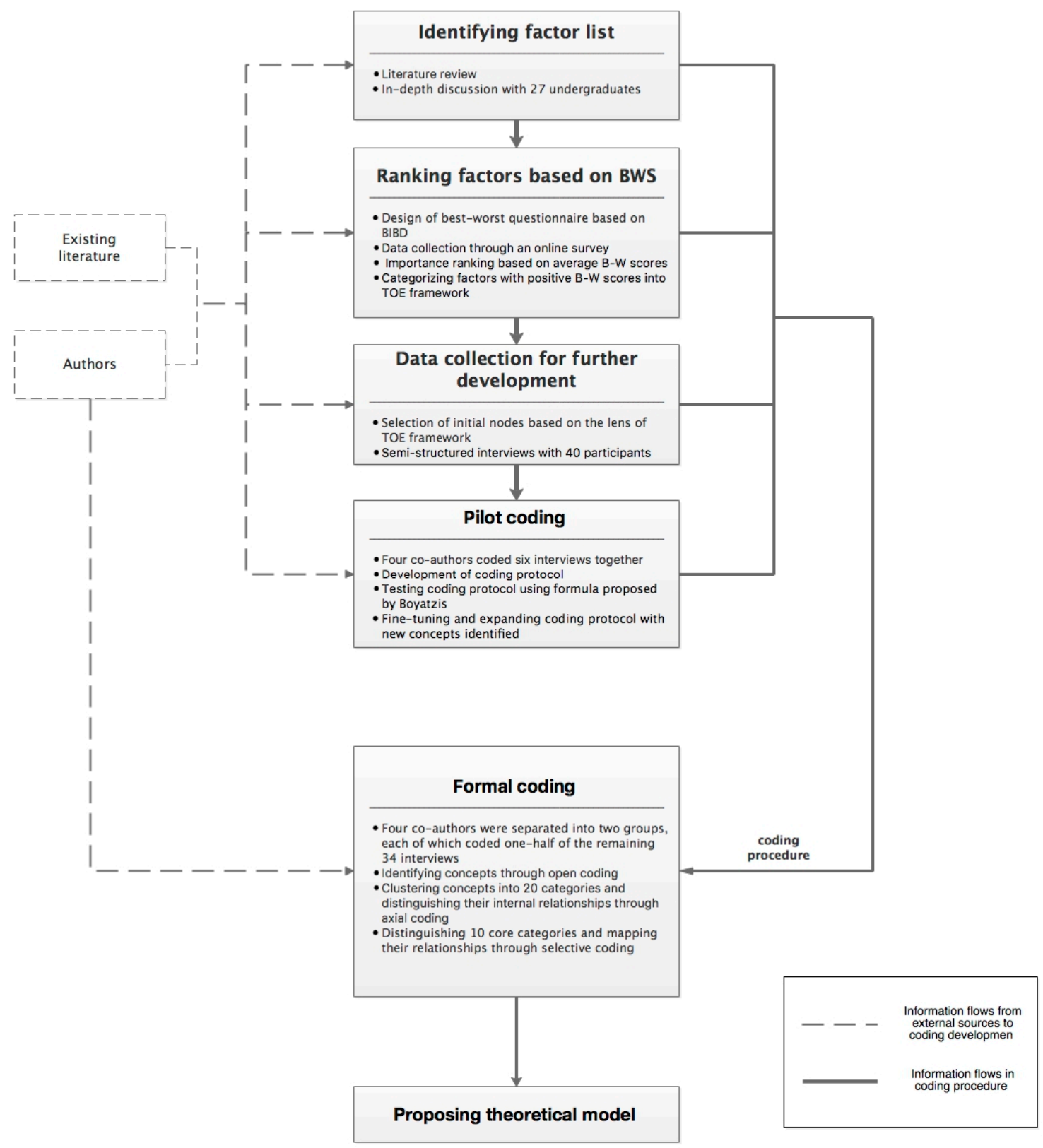

Figure 1. Whole process of the current study.

\section{Methodology}

\subsection{Best-Worst Scaling Method}

The Best-Worst Scaling (BWS) method, also known as Maximum Difference Scaling, was developed by Louviere and Woodworth (1990) and first published in 1992 [9]. The purpose of this method is to obtain the relative importance of various attributes or factors. Different from asking respondents to rank all choices directly, BWS decomposes all options into a set of choice combinations. Each choice combination is composed of the same number of options. Respondents are asked to indicate the most and the least important choice in each choice combination. This approach does not ask respondents to make a balance between all the choices, and thereafter makes it easy for respondents to make decisions in each set of choice combination and avoid evaluation bias. In addition, this technique limits the number of options in each combination to reduce respondents' cognitive difficulty in making choices [29]. Thereafter, BWS has been widely used to obtain individuals' preferences towards different aspects or attributes of the focal artifact. 


\subsection{Design of Best-Worst Questionnaire}

If we have $\mathrm{N}$ choices to compare, BWS decomposes these $\mathrm{N}$ choices into $\mathrm{M}$ choice combinations. Each choice combination, or survey question, is a subset of the $\mathrm{N}$ choices. All questions have the same amount of choices, usually four to five. Each choice will appear in $\mathrm{K}$ questions with $1<\mathrm{K}<\mathrm{M}$. BWS requires that each choice appears the same amount of times in all the questions. This assures that each choice has the same possibility to be chosen as the most or least important. Balanced incomplete block design (BIBD) is widely used in BWS research because it can produce a set of choice combinations that meet BWS requirements [30].

The specific parameters in the BWS questionnaire design should follow some criteria: the number of choices in each question is suggested to be 4 or 5 ; each choice should appear in at least 3 to 5 questions; 100 to 300 online questionnaires are recommended to guarantee that each object should appear at least 500 times [31]. In this study, the total number of choices is 25; each question includes 4 choices; each choice appears 8 times in the whole questionnaire; and we had 182 valid respondents, and thereafter each choice appeared 1456 times. The design of the questionnaire passed the test of BWS experimental design criteria. We used R software to implement the BIBD algorithm and obtained 50 questions for the survey as indicated in Table 3. Respondents were requested to choose the most and the least important options from the four options in each question. We also gave out an example of our BWS questions as indicated in Table 4.

Table 3. Design of best-worst scaling (BWS) questions.

\begin{tabular}{|c|c|c|c|c|}
\hline \multirow{2}{*}{$\begin{array}{c}\text { Question Number } \\
1\end{array}$} & \multicolumn{4}{|c|}{ Choices } \\
\hline & 24 & 23 & 14 & 20 \\
\hline 2 & 6 & 18 & 15 & 7 \\
\hline 3 & 21 & 15 & 14 & 11 \\
\hline 4 & 24 & 25 & 1 & 7 \\
\hline 5 & 4 & 10 & 23 & 15 \\
\hline 6 & 18 & 21 & 10 & 2 \\
\hline 7 & 22 & 10 & 1 & 12 \\
\hline 8 & 8 & 14 & 6 & 25 \\
\hline 9 & 10 & 5 & 24 & 6 \\
\hline 10 & 6 & 13 & 21 & 12 \\
\hline 11 & 18 & 24 & 19 & 11 \\
\hline 12 & 9 & 22 & 24 & 4 \\
\hline 13 & 3 & 6 & 4 & 20 \\
\hline 14 & 17 & 8 & 19 & 20 \\
\hline 15 & 5 & 21 & 8 & 22 \\
\hline 16 & 3 & 15 & 2 & 24 \\
\hline 17 & 3 & 25 & 18 & 13 \\
\hline 18 & 17 & 4 & 1 & 18 \\
\hline 19 & 3 & 14 & 4 & 5 \\
\hline 20 & 3 & 9 & 19 & 10 \\
\hline 21 & 23 & 21 & 16 & 3 \\
\hline 22 & 20 & 18 & 12 & 5 \\
\hline 23 & 21 & 7 & 24 & 17 \\
\hline 24 & 13 & 2 & 22 & 25 \\
\hline 25 & 2 & 11 & 5 & 1 \\
\hline 26 & 13 & 19 & 23 & 1 \\
\hline 27 & 3 & 7 & 20 & 22 \\
\hline 28 & 23 & 18 & 9 & 8 \\
\hline 29 & 1 & 8 & 15 & 20 \\
\hline 30 & 9 & 12 & 15 & 25 \\
\hline 31 & 7 & 5 & 9 & 16 \\
\hline 32 & 14 & 2 & 9 & 17 \\
\hline
\end{tabular}


Table 3. Cont.

\begin{tabular}{ccccc}
\hline Question Number & \multicolumn{4}{c}{ Choices } \\
\hline 33 & 22 & 18 & 14 & 16 \\
34 & 20 & 13 & 9 & 11 \\
35 & 17 & 10 & 14 & 13 \\
36 & 2 & 6 & 16 & 19 \\
37 & 16 & 25 & 20 & 10 \\
38 & 5 & 15 & 13 & 19 \\
39 & 2 & 4 & 8 & 12 \\
40 & 19 & 7 & 12 & 14 \\
41 & 17 & 22 & 15 & 16 \\
42 & 7 & 11 & 10 & 8 \\
43 & 2 & 23 & 7 & 12 \\
44 & 23 & 11 & 6 & 22 \\
45 & 4 & 25 & 19 & 21 \\
46 & 23 & 5 & 17 & 25 \\
47 & 4 & 11 & 1 & 16 \\
48 & 1 & 9 & 6 & 21 \\
49 & 16 & 24 & 8 & 13 \\
50 & 24 & 23 & 14 & 20 \\
\hline
\end{tabular}

Table 4. Example of BWS question.

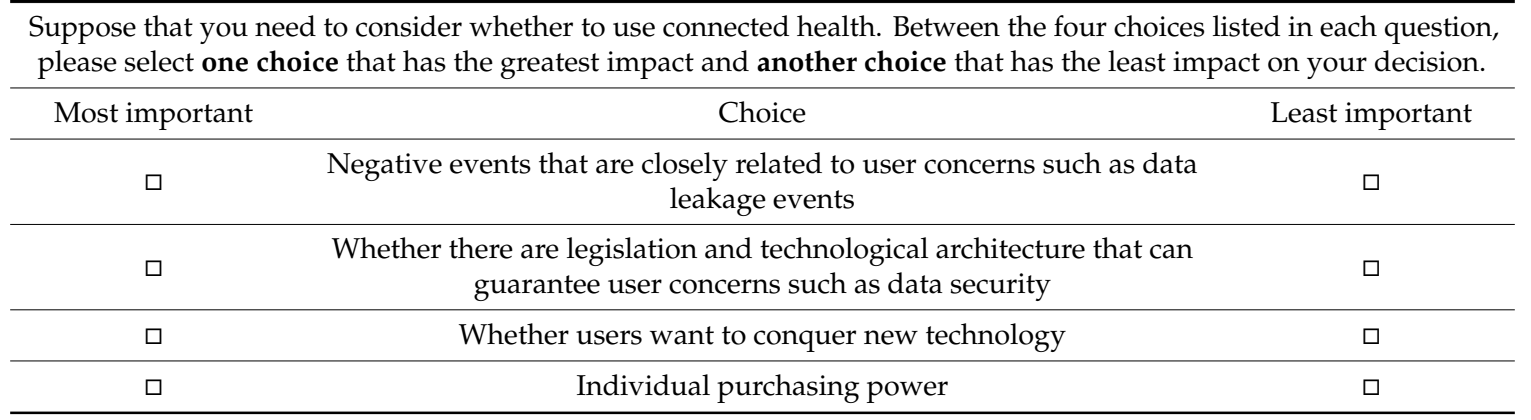

\subsection{Sample and Data Collection}

This study focused on Chinese young adults for several considerations. First, more and more young adults suffer from chronic disease because of, at least partially, their high workloads, large pressure in daily life, and unhealthy living habits. Drinking, smoking, sedentary habits, lack of exercise, unhealthy diet, and other daily behaviors have become nearly $80 \%$ of the causes of chronic diseases among young adults [32]. However, young adults are less likely to go to hospitals [11]. According to a 2014 survey of a telemedicine provider MDLive, young adults aged 18 to 34 were more likely to delay (54\%) or cancel $(72 \%)$ visits to health care providers because of "inconveniences". Thus, connected health provides a good choice for young adults. In addition, the elderly usually distrust new technologies and their ability to use new technology is low. It will be a challenge for them to accept connected health [26]. Young adults are more familiar with wearable devices and more adaptable to new electronics [11,23]. They may persuade their parents and grandparents to use connected health after they accept it. Thus, it is wise for us to focus on young adults in this study.

Data was collected in June 2018 by conducting an online survey. The snowball sampling, a way of gathering information through personal relationship networks, was deployed to collect the data [33]. It can spread the questionnaire among the target population more accurately [34]. The survey included two sections: the first section is the 50 questions listed in Table 3, and the second section collects the demographic information of respondents, including gender, age, educational background, and number of wearable devices that they have used. Finally, 217 complete questionnaires were collected, and 182 valid questionnaires were ultimately used for data analysis after data screening. There were 109 females 
$(59.9 \%)$ and 73 males (40.1\%). As for the educational background, there were 159 undergraduates (87.4\%), 20 Masters $(11.0 \%)$ and three PhDs (1.6\%). With regard to the age, there were 68 respondents $(37.4 \%)$ that were 18 to 20 years old, $95(52.2 \%)$ that were 21 to 23 years old, and $19(10.4 \%)$ that were 24 to 27 years old. A total of 66 (36.3\%) respondents had never used a wearable device, $96(52.7 \%)$ had used at least one wearable device, and $20(11.0 \%)$ had used two or more wearable devices.

\section{Data Analysis}

\subsection{Absolute Importance of 25 Factors}

BWS method provides an approach to analyze the absolute importance of the 25 factors and obtain their ranking through calculating the average B-W scores of each factor. A factor will obtain one point for every time it is chosen as the most important factor, while it will obtain a negative one point for every time it is chosen as the least important factor. As we mentioned before, each factor appeared eight times in the whole questionnaire, and thereafter the maximum times it was chosen as the most important factor is eight and the maximum times it was chosen as the least important factor is also eight. Total best means the times one factor is chosen as the most important factor, and total worst means the time that it is selected as the least important factor. This study had 182 respondents, and thus each factor appeared 1456 times $(182 * 8)$ in the sample. The maximum number for total best and total worst is 1456 . The $\mathrm{B}-\mathrm{W}$ score for one factor is the number of times it is chosen as the most important factor minus the number of times it is chosen as the least important factor. The average B-W score of that factor is its B-W score divided by the number of times it appears in the questionnaire of all respondents [33]. A positive B-W score means that the factor is more likely to be chosen as the most important factor by the respondents, while a negative average $B-W$ score means that the factor is more likely to be chosen as the least important by the respondents [29]. BWS technique allows us to rank the importance of factors according to their B-W scores or average B-W scores. Figure 2 displays the average $\mathrm{B}-\mathrm{W}$ scores and their ranking. Histograms above the $\mathrm{X}$-axis demonstrate positive average $\mathrm{B}-\mathrm{W}$ scores, and histograms below the $\mathrm{X}$-axis demonstrate negative average $\mathrm{B}-\mathrm{W}$ scores.

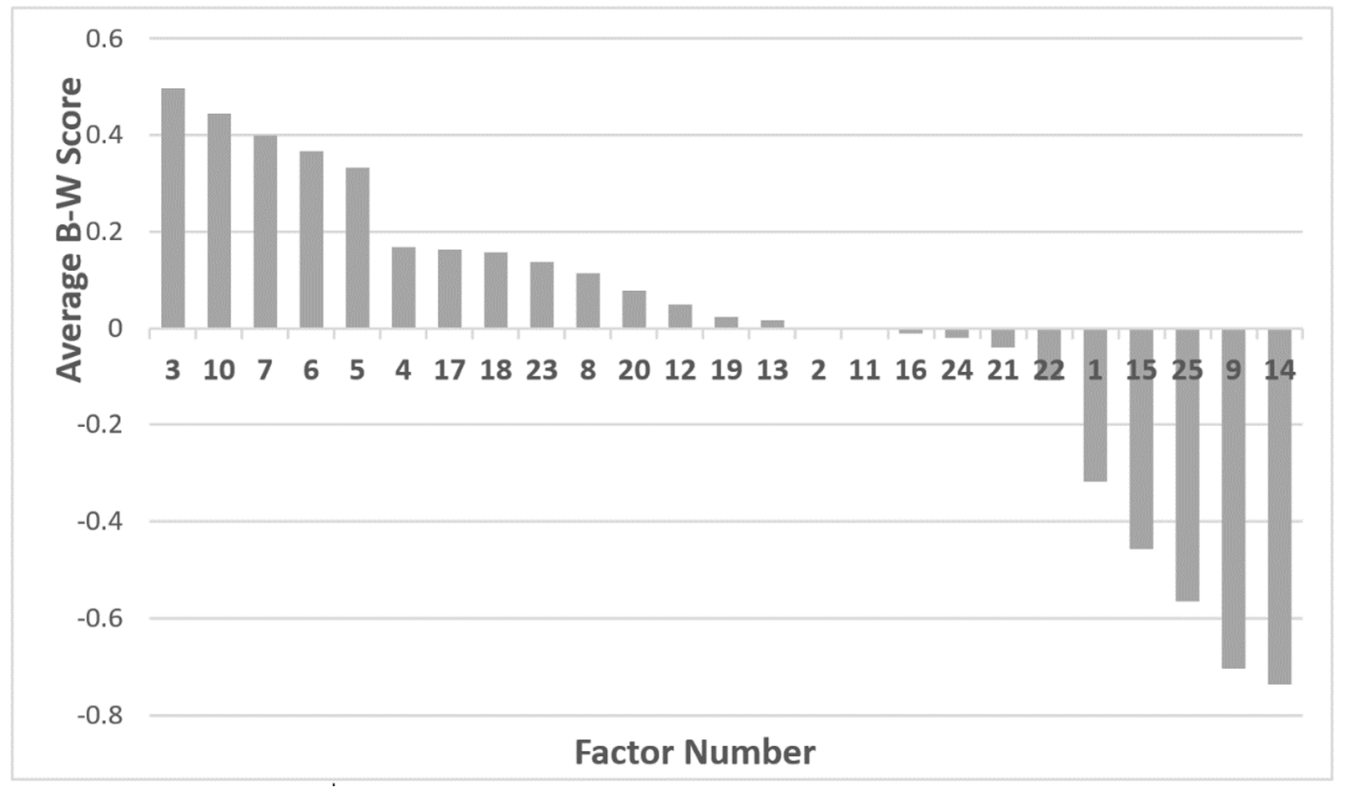

Figure 2. Average B-W scores of 25 affecting factors.

Detailed information can be found in Table 5, which presents total best, total worst, B-W score, average B-W score, and standard deviation of B-W for each factor. The results demonstrate whether respondents view a factor as important and display the ranking of importance for all factors. 
For example, health damage is the most important factor that will affect individuals' acceptance of connected health, while innovativeness is the least important factor.

Table 5. Importance of 25 factors ranked by average B-W scores.

\begin{tabular}{|c|c|c|c|c|c|c|}
\hline Factor No. & Factor & Total Best & Total Worst & B-W Score & Average B-W Score & Std of B-W \\
\hline 3 & Health damage & 780 & 57 & 723 & 0.497 & 3.023 \\
\hline 10 & Basic service & 728 & 81 & 647 & 0.444 & 2.521 \\
\hline 7 & Active feedback & 663 & 80 & 583 & 0.4 & 2.451 \\
\hline 6 & Analytical reliability & 616 & 82 & 534 & 0.367 & 2.451 \\
\hline 5 & Device accuracy & 594 & 108 & 486 & 0.334 & 2.652 \\
\hline 4 & Data security & 433 & 188 & 245 & 0.168 & 2.556 \\
\hline 23 & Institutional architecture & 360 & 158 & 202 & 0.139 & 2.822 \\
\hline 8 & Device cost & 416 & 249 & 167 & 0.115 & 3.146 \\
\hline 20 & Purchasing power & 475 & 361 & 114 & 0.078 & 4.776 \\
\hline 12 & Savings in medical expenditure & 385 & 313 & 72 & 0.049 & 3.417 \\
\hline 19 & Privacy concern & 263 & 227 & 36 & 0.025 & 3.167 \\
\hline 13 & Optimism & 332 & 306 & 26 & 0.018 & 3.255 \\
\hline 24 & Negative events & 294 & 321 & -27 & -0.019 & 3.507 \\
\hline 21 & Social influence & 353 & 409 & -56 & -0.038 & 3.9 \\
\hline 22 & Government policy & 228 & 385 & -157 & -0.108 & 3.036 \\
\hline 1 & Ease of use & 126 & 590 & -464 & -0.319 & 2.899 \\
\hline 15 & Discomfort & 149 & 815 & -666 & -0.457 & 3.699 \\
\hline 25 & Popularity & 28 & 850 & -822 & -0.565 & 2.279 \\
\hline 9 & Aesthetic & 46 & 1070 & -1024 & -0.703 & 2.76 \\
\hline 14 & Innovativeness & 19 & 1090 & -1071 & -0.736 & 2.042 \\
\hline
\end{tabular}

\subsection{TOE Framework of Factors Affecting Connected Health Acceptance}

The past section distinguished 15 factors with positive B-W scores. We reorganized the 25 factors in Table 6. Nine out of twelve technological factors had positive B-W scores, which included health damage, basic service of connected health, active feedback, analytical reliability, device accuracy, data security, device cost, savings in medical expenditure, and device specifications from high to low. Five out of eight individual factors had positive B-W scores, which were trust, health concern, purchasing power, privacy concern, and optimism from high to low. Only institutional architecture matters in environmental factors.

Table 6. Technology-organization-environment (TOE) framework after data analysis.

\begin{tabular}{|c|c|c|c|}
\hline & Technological Factors & Individual Factors & Environmental Factors \\
\hline $\begin{array}{l}\text { Most } \\
\text { important } \\
(\mathrm{B}-\mathrm{W}>0)\end{array}$ & $\begin{array}{ll}\text { 1. } & \text { Health damage }(\# 3) \\
\text { 2. } & \text { Basic service of connected health }(\# 10) \\
\text { 3. } & \text { Active feedback (\#7) } \\
\text { 4. } & \text { Analytical reliability }(\# 6) \\
\text { 5. } & \text { Device accuracy (\#5) } \\
\text { 6. } & \text { Data security }(\# 4) \\
\text { 7. } & \text { Device cost }(\# 8) \\
\text { 8. } & \text { Savings in medical expenditure (\#12) } \\
\text { 9. } & \text { Device specifications }(\# 2)\end{array}$ & $\begin{array}{ll}\text { 1. } & \text { Trust }(\# 17) \\
\text { 2. } & \text { Health concern }(\# 18) \\
\text { 3. } & \text { Purchasing power }(\# 20) \\
\text { 4. } & \text { Privacy concern }(\# 19) \\
\text { 5. } & \text { Optimism }(\# 13)\end{array}$ & Institutional architecture (\#23) \\
\hline $\begin{array}{l}\text { Least } \\
\text { important } \\
(\mathrm{B}-\mathrm{W}<0)\end{array}$ & $\begin{array}{l}\text { 1. Personalized service of connected health }(\# 11) \\
\text { 2. Ease of use }(\# 1) \\
\text { 3. }\end{array}$ & $\begin{array}{ll}\text { 1. } & \text { Insecurity (\#16) } \\
\text { 2. } & \text { Discomfort (\#15) } \\
\text { 3. } & \text { Innovativeness (\#14) }\end{array}$ & $\begin{array}{ll}\text { 1. } & \text { Negative events }(\# 24) \\
\text { 2. } & \text { Social influence }(\# 21) \\
\text { 3. } & \text { Government policy }(\# 22) \\
\text { 4. } & \text { Popularity }(\# 25)\end{array}$ \\
\hline
\end{tabular}




\subsection{Heterogeneity of Factor Importance}

Although we have obtained the absolute importance of all factors based on average B-W scores, we still do not know whether the results are due to aggregating unequal preferences of respondents. Take "device specifications" as an example, it has an average B-W score of 0.001 . There are different possibilities that may lead to this outcome. For example, maybe most respondents consider it a factor with moderate importance, and maybe half the respondents consider it the most important factor and the other half consider it the least important factor. We calculated the standard deviation of the best-worst scores to determine how much reported factor importance varies across the whole sample. Figure 3 visualized the combination of factor importance and heterogeneity.

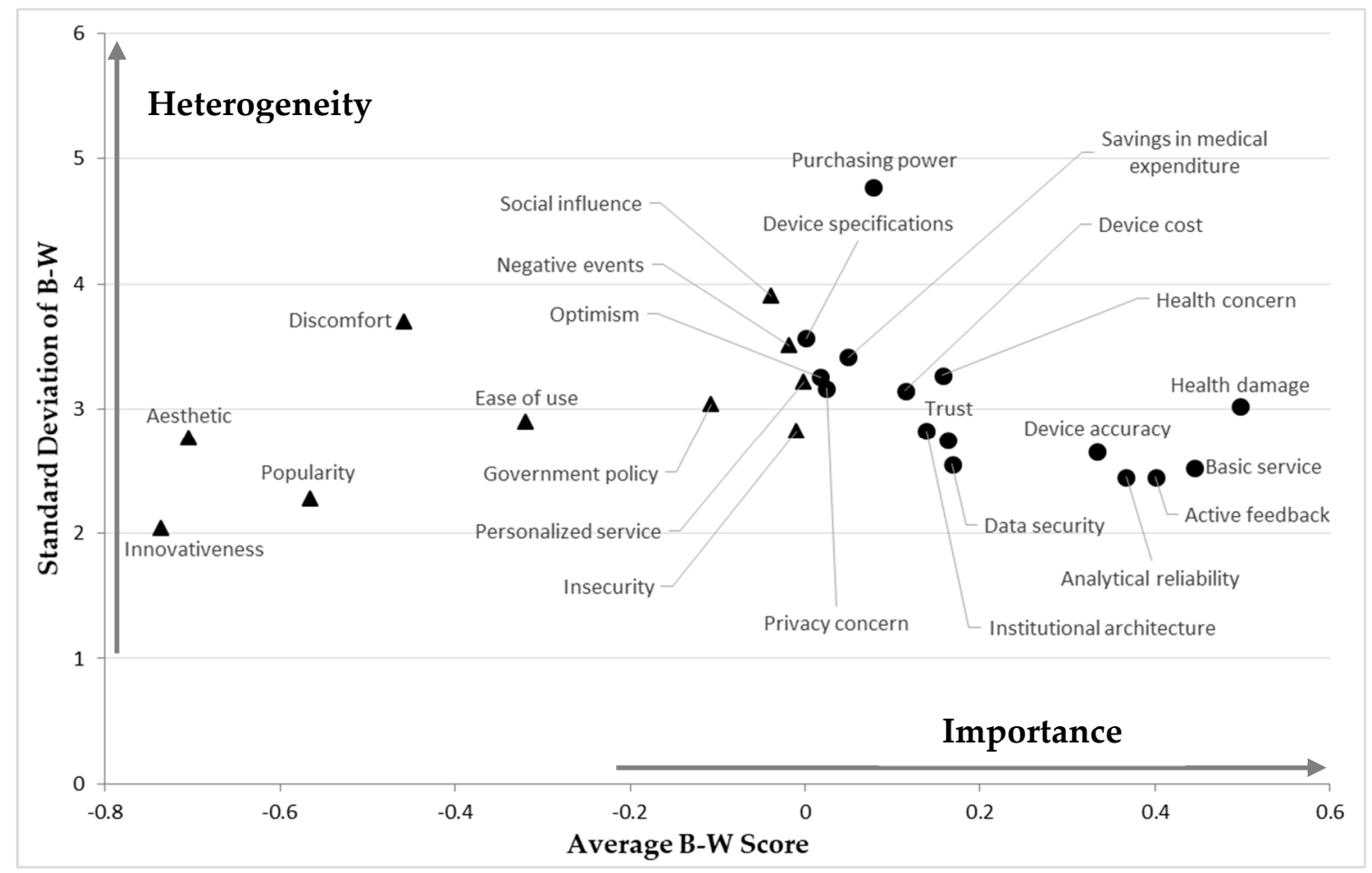

Figure 3. Average B-W Score and standard deviation of B-W. Notes: The triangles represent factors with negative average $\mathrm{B}-\mathrm{W}$ scores, while the circles represent factors with positive average $\mathrm{B}-\mathrm{W}$ scores.

Government and practitioners of the connected health industry should pay attention to factors in the right-lower side of Figure 3 since it reflects that most respondents agree with the importance of those factors. Device accuracy, analytical reliability, active feedback, basic service, and health damage are some factors located in the right-lower side. Stakeholders of the connected health industry should also pay special attention to factors with high heterogeneity and reasonable importance. This implies that those factors are very important to a subset of users. Device cost, health concerns, and savings in medical expenditure are some examples.

\section{Development of Theoretical Model}

To explore how factors affected users' acceptance of connected health, we conducted a qualitative study based on grounded theory (GT). Its core purpose is to generate theory from data through robust and systematic processes, analytical skills, and theoretical sensitivity [35-38]. Past literature has verified its suitability in building theoretical models in the emerging research field [39]. Considering that connected health is relatively new and there are few relevant studies, we chose GT as our research method. GT has three main coding techniques including open coding, axial coding, and selective coding [36]. Open coding involves a deep reading to identify concepts among information and 
data; axial coding requires researchers to classify these concepts, integrate them into categories and explore the relationships among the categories; selective coding involves clustering categories into core categories, further exploration in the relationships among core categories, and refining the theoretical model [40].

\subsection{Data Collection}

Grounded theory requires us to conduct content analysis with an "open mind," but not with an "empty head" [41]. A key guideline of past literature using grounded theory is that we should relate the current study to the broader literature and adopt a "low level theory" to start the content analysis [37]. This study adopted the lens of the TOE framework to start our content analysis since it is a "low level theory" that is well accepted and we have obtained the relative importance of factors in different categories as listed in Table 6. When we chose the initial nodes, we preferred to select a balanced factor panel from all three dimensions of the framework. It is reasonable to choose top ranking factors in each dimension. However, there is no rule of thumb to decide how many factors we should include in each dimension. We used the following criteria to select initial nodes that will be used in the semi-structured interview. First, the factor should have a positive B-W score; second, more than half the respondents have chosen the factor as the most important factor at least once; and third, the number of total worst should be contributed by at most one half of the total number of respondents. Finally, eight factors were included in the interview as initial nodes, which were health damage, active feedback, device accuracy, analytical reliability, basic service, trust, privacy concern, and institutional architecture. These initial nodes match the ranking of most important factors in each dimension in Table 6.

Data was collected through semi-structured interviews. At the beginning, we explained the definitions of connected health and initial nodes, and introduced some examples of connected health. Then, we conducted in-depth interviews to explore whether and how these eight factors affect interviewees' acceptance of connected health. We welcomed additional variables that would affect their adoption during the interview. We selected 40 interviewees aged between 30 and 50. Among the 40 interviewees, 17 were male $(42.5 \%)$ and 23 were female $(57.5 \%)$; 3 were under 20 years old $(7.5 \%)$, 32 were between 20 and 30 years old $(80 \%)$, 4 were between 30 and 50 years old $(10 \%)$ and 1 was over 50 years old (2.5\%). Each interview lasted for 30 to $40 \mathrm{~min}$, and we recorded the interviews with the consent of the interviewees. After all interviews were completed, we transcribed the recording into text materials for further coding.

\subsection{Data Analysis}

NVivo 11, a popular content analysis software, was used to analyze the transcribed interviews. The current study adopted three coding techniques of GT. In the first step of open coding, we selected six interviews and four co-authors coded them together to develop the coding protocol. They discussed the identified concepts to reach an agreement on concept definitions. This guaranteed that all coders have the same understanding of the same concepts. Subsequently, the four co-authors were separated into two groups. Each group coded one-half of the remaining 34 interviews. We relied on inter-coder agreement and consensus to validate new codes, if any. To ensure the reliability and consistency of our coding, we calculated the reliability according to the formula of Boyatzis [42]:

$$
R=\frac{n \times k}{1+(n-1) \times k}
$$

where $R$ is the reliability; $n$ is the sample number; $k$ is the mutual agreement between two researchers. This study adopted the average of the mutual agreement of the four researchers, and its formula is as follows:

$$
k=\frac{2 M}{N_{1}+N_{2}}
$$


where $M$ is the completely unified coding number of two researchers; $N_{1}$ and $N_{2}$ represent the total coding number of the first and second researchers. The reliability calculated by the above formula is 0.99 , higher than the critical value of 0.7 , indicating that our coding is reliable after discussion.

After open coding, axial coding was conducted to cluster concepts coded in the open coding period into different categories and discover relationships between concepts and categories. Twenty categories of concepts were summarized based on a thorough discussion of the four co-authors, and each category included concepts that are closely related. Then, we performed the first section of selective coding and clustered the 20 categories into 10 core categories as displayed in Figure 4. Each of these 10 core categories will be discussed in the following section.

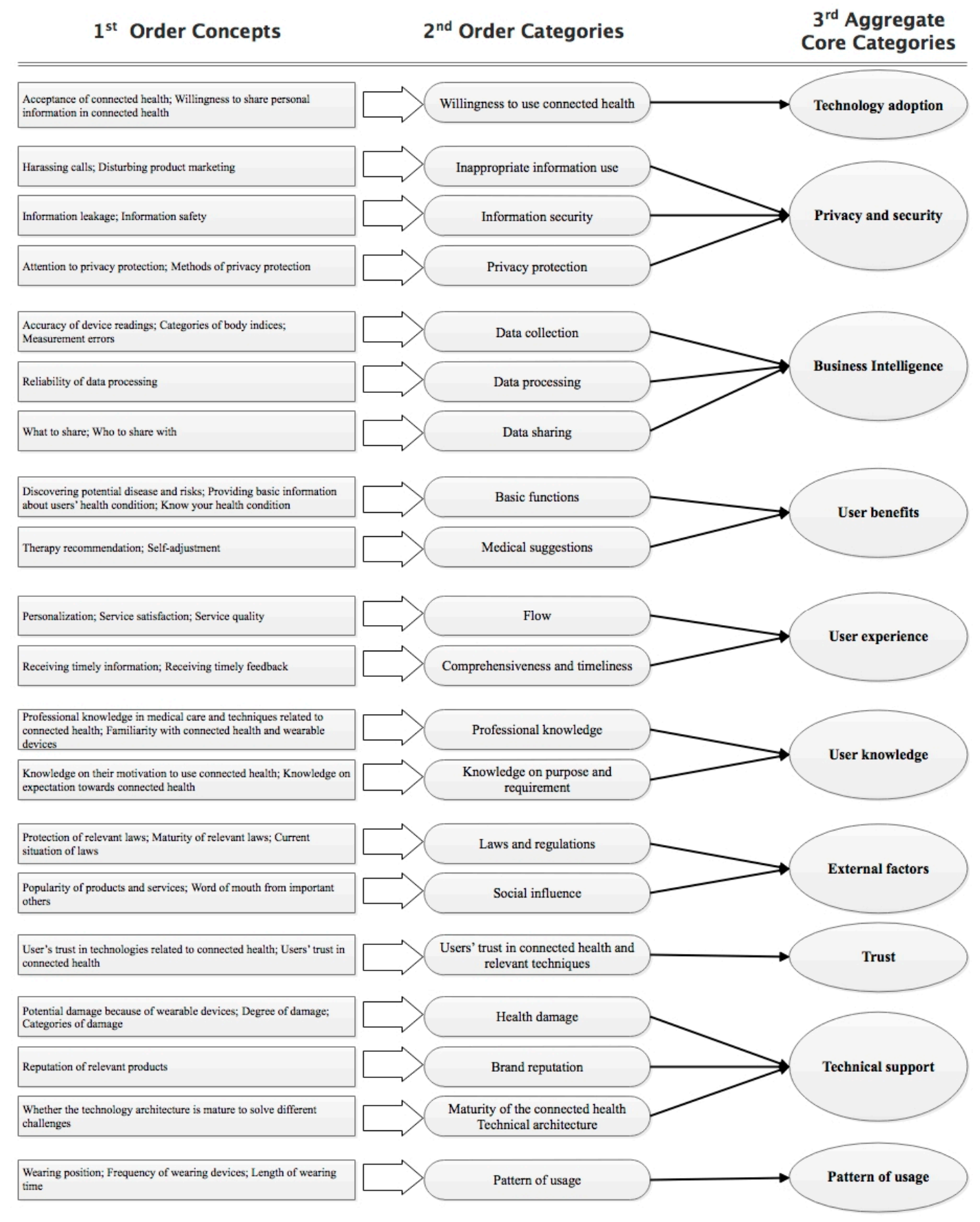

Figure 4. Emerging concepts, categories, and core categories. 


\subsubsection{Technology Adoption}

Given that the current study hopes to explore factors affecting individuals' acceptance of connected health, we view technology adoption as the dependent variable. Technology adoption represents people's willingness to use connected health, which includes two aspects of meanings. First, individuals intend to accept the connected health model as a medical service mode, and second, they prefer to share information when using the connected health since information sharing is essential in connected health.

\subsubsection{Privacy and Security}

The term privacy and security represents individuals' concern on different aspects of the safety of their information shared in the process of connected health. The first one is inappropriate use of their personal information. For example, they worry that third parties will use their information to conduct harassing calls or disturbing marketing. For example, one interviewee mentioned that, "I do not want to give my information to insurance companies because they often call to introduce a variety of their products. I feel that they will not protect my privacy". The second aspect is individuals' concern on the status of privacy and security protection in our society. Information leakage in the real world will decrease individuals' intention to use connected health service. The third aspect is individuals' requirement of privacy and security protection. They mentioned that they would try connected health if it protects their privacy and security.

\subsubsection{Business Intelligence}

Business intelligence here refers to the capacity of connected health to collect personal data, integrate data of the whole medical process, and analyze the integrated dataset to provide medical suggestions for patients. We distinguished three aspects of business intelligence that will affect their acceptance of connected health, which are data collection, data processing, and data sharing. Data collection refers to individuals' concern of whether connected health can rely on techniques such as wearable devices to accurately collect personal information, especially health related indications. The value of connected health rests on information sharing among different stakeholders in the medical industry such as clinics, hospital, and gyms. For example, many applications such as Nike+ record how many steps their users walk every day. If an individual shared this information with insurance companies, insurance companies can offer a better rate for his or her insurance. Thus, data sharing determines whether we can obtain a whole picture of an individual's health condition. Data processing refers whether connected health is capable of turning integrated data into insights. For example, one interviewee mentioned that, "if there are any techniques and algorithms that can analyze the data and give us a suggestion, we may believe it is reliable".

\subsubsection{User Benefits}

User benefits refer to basic functions and medical suggestions that connected health can offer users. Connected health can offer different types of basic services, such as providing basic information about users' health condition and allowing users to know their health status. Apart from these basic services, connected health can offer its users some advanced services. For example, connected health can help people distinguish potential diseases and health risks by continuously collecting health medications. Apart from this, connected health can also alert individuals to the consequences of their bad habits and offer individuals suggestions on self-adjustment. For patients who use connected health, the service can also help physicians verify the effectiveness of therapy and distinguish better treatment if any.

\subsubsection{User Experience}

User experience refers to user's perception and evaluation of connected health service. The current study obtains users' major concern of the connected health service. They expect that connected health can offer personalized and high-quality services and increase their service satisfaction. Meanwhile, 
they hope that connected health can offer feedback and suggestions in a comprehensive and timely manner.

\subsubsection{User Knowledge}

The current study distinguished two types of user knowledge that affect individuals' acceptance of connected health. The first is their professional knowledge of medical care and techniques related to connected health such as wearable devices. The other one is knowledge on their motivation to use connected health and expectations towards connected health. According to our coding, we found that interviewees who know better about their motivation and expectations towards connected health express a higher level of intention to use connected health service.

\subsubsection{External Factors}

This study summarized two types of influences that come from the external environment, which are laws and regulations and social influence. Law and regulations refer to whether the government establishes laws and regulations to protect the rights and interests of connected health users. Some interviewees mentioned that they are more likely to use connected health if current laws protect their rights when using connected health. For example, "If there are no necessary laws and regulations about connected health, it will not make a big difference to the current situation of connected health. Thus, it is good to promote the introduction of relevant laws and regulations". Social influence refers to recommendation from important others. An individual is more likely to accept connected health if important others are using it or recommend him or her to use it.

\subsubsection{Trust in Connected Health}

Past literature has demonstrated that potential users' trust in an IT artifact is an important predictor of technology acceptance. When it comes to the context of connected health, trust also matters to the acceptance of connected health. Interviewees mentioned that they are less likely to choose the product if they do not trust connected health.

\subsubsection{Technical Support}

Technical support involves health damage, brand reputation, and mature technology architecture. Users need to wear devices to collect health information. Interviewees pay attention to whether these technologies will bring damage for their health. For example, some manufacturers may use toxic materials and some products may cause radiation. Brand reputation is another feature that interviewees consider because products with a high reputation are less likely to cause damage for users. In addition, some interviewees also mentioned that mature technology architecture determines the reliability of connected health and thereafter affects users' acceptance of connected health.

\subsubsection{Pattern of Usage}

Pattern of usage refers to how connected health collects personal body indications. For example, as an essential component of connected health, wearable devices collect data by touching specific parts of the human body. Different types of wearable devices have different wearing patterns. For example, where to wear the devices and whether users should wear the devices continuously.

\subsection{Conceptual Model from Selective Coding}

After the first step of selective coding, the four co-authors went back to the transcribed text to distinguish the relationships among core categories. We concentrated on relationships that occurred more than five times in transcribed texts and obtained the conceptual model in Figure 5. According to the model, business intelligence and technical support belongs to the technological dimension; user benefits, user experience, trust in connected health, user knowledge, and privacy/security pertains 
to the individual dimension; and external factors reflect the environmental dimension. The TOE framework supports the explanation power of the proposed conceptual model.

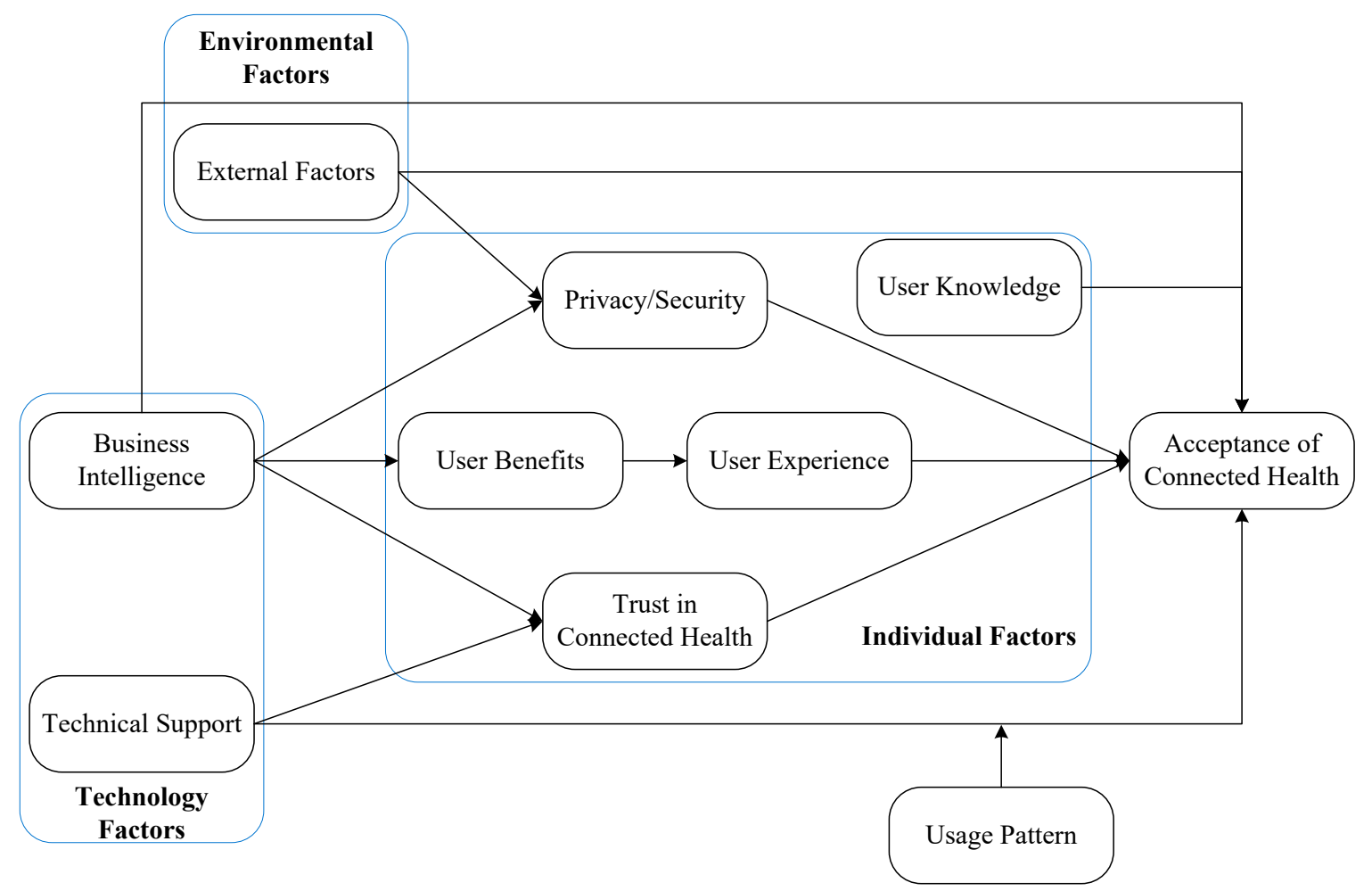

Figure 5. Revised TOE framework after selective coding.

Our study also clarified the correlations among different factors and their paths of affecting individuals' acceptance of connected health. According to the model, seven core categories directly affect individuals' acceptance of connected health; they include user knowledge, external factors, business intelligence, privacy/security, user experience, trust in connected health, and technical support. In addition, three core categories will indirectly affect users' acceptance decision, including external factors, business intelligence, and technical support. External factors not only have a direct impact on adoption of connected health, but also has an indirect relationship with adoption of connected health via privacy and security. In addition, technical support will affect individuals' trust in connected health and thereafter influence their acceptance of connected health. Based on the transcribed text, business intelligence of connected health is the most important core category since it not only directly affects adoption decision, but also influences adoption in different approaches. Business intelligence will change individuals' perception in privacy/security and trust in connected health, which will affect their acceptance of connected health. Meanwhile, business intelligence will influence users' benefits, which will improve their user experience and thereafter affect their adoption decision.

Apart from the direct and indirect relationship we mentioned above, we also distinguished a moderation effect of usage pattern. Some interviewees mentioned that the importance of technical support depends on the usage pattern. For example, if users should wear wearable devices at all times, they will pay more attention to technical support such as device damage when they make acceptance decisions.

\section{Discussion}

This study summarized 25 potential factors that may affect Chinese young adults' acceptance of connected health. We ranked the importance of those factors by analyzing data collected from an online survey using the BWS method. We found that health damage of wearable devices is the 
most important factor in technological dimension. This is reasonable since connected health system is proposed to provide quality medical care in an effective and efficient approach. Individuals will not be likely to accept an IT artifact if it will lead to health damage. Individuals' trust in connected health is the most important factor in individual dimension. This is because connected health is relatively new and individuals have a high level of uncertainty towards connected health. Trust is necessary under this circumstance to facilitate individuals to accept connected health. Only one environmental factor, institutional architecture, will affect individuals' acceptance of connected health. This suggests that our government should develop legislation and technological architecture that can guarantee user concerns. This serves as an endorsement by the government and facilitates individuals to accept connected health. The current study also conducted a qualitative study based on grounded theory to explore how different nodes affect individuals' acceptance of connected health. Finally, we distinguished nine core categories that will affect individuals' acceptance of connected health as displayed in Figure 5.

\subsection{Theoretical Implication}

This study contributes to research on acceptance of connected health. The term connected health is relatively new in China, although it is promising in coping with healthcare challenges. The advancement of technology facilitates the feasibility of connected health system. However, there is a lack of systematic research on factors affecting individuals' acceptance of connected health. This is not good for realizing the great potential of connected health. In this study, 25 factors are summarized as potential factors that will affect connected health acceptance based on a thorough literature review and in-depth discussion. This provides a factor list for future academic research on the acceptance of connected health.

In addition, past literature primarily focuses on technology aspects, such as how to achieve data analysis ability of connected health and how to guarantee wearable technology security and information safety. However, patients, not technology, are the focal stakeholders in medical care industry. Technology is just a tool that can help realize the objectives of connected health. More studies should explore human factors affecting individuals' acceptance of connected health. This study introduces two additional dimensions other than technological factors, which are individual factors and environment factors by adopting the technology-organization-environment framework. Apart from twelve technological factors, the individual factors include nine potential factors and the environment factors include five potential factors.

This study applies the BWS method to rank the importance of those 25 factors. The study demonstrates fifteen factors with positive B-W scores, including nine technological factors, five individual factors, and one environmental factor. We can see that technological factors are important, but individual factors are also important in determining individuals' acceptance of connected health. However, Chinese young adults do not think the environmental factor is important. The results deepen our understanding of important factors affecting Chinese young adults' acceptance of connected health. The categorization of important factors in three dimensions of the TOE framework also provides theoretical support for future research on acceptance of connected health.

The study also depends our understanding of how different factors affect individuals' acceptance of connected health. This study proposes a conceptual model as indicated in Figure 5. The model suggests that seven factors will directly affect individuals' acceptance of connected health. Meanwhile, three factors will indirectly influence individuals' acceptance decisions. Also, the model includes a usage pattern as a moderator that will affect the importance of technical support in affecting acceptance decisions. This study is among the first wave of articles that try to explore factors affecting consumers' intention to use connected health.

\subsection{Practical Implication}

The current medical care industry faces several challenges, while health authorities are trying to make a balance between quality and cost of medical service. It is important to facilitate the 
collaboration among stakeholders in the medical care industry to realize the sustainability of a medical care system that will meet the three-bottom line, or economic, environmental, and social factors [34]. In connected health, different stakeholders are connected through timely information sharing [17]. This full connection makes it possible for patients to receive care in a proactive and efficient manner. Thus, connected health helps build a sustainable medical care industry. This study explores important factors affecting connected health acceptance, supporting the building of sustainable medical care system and a sustainable society.

Hospital suppliers such as device manufacturers, the government, and patients are the main stakeholders of the medical care delivery process [16]. Our results provide some suggestions for these main stakeholders. From the perspective of infrastructure manufacturers, they should know that Chinese young adults emphasize whether wearable devices will cause health damage to users, whether the test results of wearable devices are accurate, whether technology can guarantee data security in data transfer process, whether devices are affordable to common users, and whether the device is of high function performance. For medical organizations such as hospitals, they should realize that basic services such as blood glucose monitoring, chronic disease management, and identification of hidden health risks are more attractive than personalized services, such as customized medical service and treatment protocols. Moreover, medical organizations should perform reliable analysis using the data collected and integrated in the connected health systems and provide active feedback for connected health users.

In China, most medical organizations are state-owned, and our government affords a large part of the medical expenses of citizens. Health authorities are trying to find a feasible solution to balance quality and cost of medical services, and connected health is a promising solution. They should consider factors that concerned respondents when designing the connected health system. For example, institutional architecture is the only important environmental factor that will affect Chinese young adults' acceptance of connected health. The government should pay attention to legislation and technological architecture.

The study also provides some suggestions on how to distinguish potential users of connected health services. Results indicate that trust, health concern, purchasing power, privacy concern, and optimism are important individual factors that will affect their acceptance of connected health. People who trust in connected health, put more emphasis on their health, have a purchasing power, and are optimistic in new technology artifacts are more likely to accept connected health. For example, exercisers are usually more concerned with their health and thereafter may be more likely to adopt connected health.

\subsection{Limitations}

The results should be interpreted with several limitations in mind. First, our samples are young adults exclusively from China. This may affect the generalizability of relevant results. Future research should collect data from the elderly and from other countries to test the validity of our results. Second, the study ranks the importance of 25 factors by using the best-worst scaling method. Thus, our study has some intrinsic limitations of BWS. For example, factors in a choice combination of the BWS questionnaire may be correlated and exhibit a degree of similarity. This issue may affect respondents' decision rules and affect the results of BWS [43]. In addition, respondents should select one most important choice and one least important choice from each choice combinations listed in Table 4. We may obtain alternative sets of BWS items by performing BIBD. The results may alter if we use an alternative BWS question list. Third, this study further explores how different factors affect consumers' acceptance of connected health by performing a qualitative study based on grounded theory. The current study therefore has limitations inherent in grounded theory research, such as "not being able to produce statistical generalizability and to be limited to the observed case, and thus running the risk of missing aspects of the phenomenon that can be significant" (p. 32) [44]. However, our target of using grounded theory is to explain what we observe and propose a conceptual model 
based on the obtained contents. Future study should test the model using empirical methods such as a survey. Fourth, this study adopts the TOE framework as the theoretical lens. There are different theories that can explain individuals' acceptance of IT artifacts. Adopting an alternative theoretical lens in a future study may lead to additional insights regarding the mechanisms through which different factors affect individuals' acceptance of connected health. More studies are needed to enhance the conceptual model of connected health adoption.

\section{Conclusions}

The global health care industry faces challenges such as an aging population, a higher rate of chronic diseases, rejuvenation of chronic disease patients, insufficient medical resources, and uneven allocation of high-quality medical resources. These challenges impede the establishment of a sustainable medical care system. Connected health is able to help cope with these challenges and has attracted more and more attention of academic researchers and practical managers. However, there is a lack of research on the adoption of connected health, and therefore its acceptance rate is still low. In addition, past literature on connected health primarily focused on technological factors while neglecting human factors. This study summarized 25 potential factors that may affect the acceptance of connected health and introduced two additional dimensions other than technological factors, which are individual factors and environmental factors, by adopting the TOE framework. To verify the importance of those 25 potential factors, this study used the best-worst scaling method to collect data and rank the absolute importance of those factors based on their average B-W scores. Finally, 15 important factors were distinguished, which included nine technological factors, five individual factors, and one environmental factor. We further performed a qualitative study based on grounded theory to explore how different factors affect individuals' acceptance of connected health. According to content analysis, we proposed a conceptual model explaining how different factors affect individuals' acceptance of connected health. This study depends on our understanding of the acceptance of connected health, and inspires more researchers to explore mechanisms through which important factors affect individuals' acceptance decision. This study also helps build a sustainable medical care system that will benefit both patients and society.

Author Contributions: L.J. conceived and designed the research and performed the online survey; Y.T., F.H., Y.Z. (Yi Zhou), C.Z. and Y.Z. (Yufei Zhang) performed the semi-structure review and conducted the content analysis; L.J., F.H., Y.Z. (Yi Zhou), Y.Z. (Yufei Zhang) prepared for the submission manuscript; L.J. oversaw the research and project funding and contributed ideas and revisions to subsequent iterations of the article.

Funding: This study is supported by the National Natural Science Foundation of China (Grant ID: NSFC 71602009); Special Fund for Joint Development Program of Beijing Municipal Commission of Education; Beijing Institute of Technology Research Fund Program for Young Scholars; Beijing Institute of Technology Basic Research Fund Program (Grant ID: 20172142005).

Acknowledgments: We thank Yingbing Shi, Xiaoxia Tian, and Yu Xi from School of Management and Economics, Beijing Institute of Technology for their help in the data collection.

Conflicts of Interest: The authors declare no conflicts of interest.

\section{References}

1. Barr, P.J.; Mcelnay, J.C.; Hughes, C.M. Connected health care: The future of health care and the role of the pharmacist. J. Eval. Clin. Pract. 2012, 18, 56-62. [CrossRef] [PubMed]

2. World Health Organization. WHO Guidelines on Integrated Care for Older People. 2017. Available online: http://www.who.int/ageing/publications/guidelines-icope/en/ (accessed on 1 March 2019).

3. Accenture. Making the Case for Connected Health. 2012. Available online: https://www.accenture.com/usen/insight-making-casvane-connected-health (accessed on 1 March 2019).

4. Barr, P.J.; Brady, S.C.; Hughes, C.M.; Mcelnay, J.C. Public knowledge and perceptions of connected health. J. Eval. Clin. Pract. 2014, 20, 246-254. [CrossRef] [PubMed]

5. Cavicchi, C.; Vagnoni, E. Does intellectual capital promote the shift of healthcare organizations towards sustainable development? Evidence from Italy. J. Clean. Prod. 2017, 153, 275-286. [CrossRef] 
6. Chouvarda, I.G.; Goulis, D.G.; Lambrinoudaki, I. Connected health and integrated care: Toward new models for chronic disease management. Maturitas 2015, 82, 22-27. [CrossRef] [PubMed]

7. Zhai, X.J.; Ali, A.A.S.; Amira, A.; Bensaali, F. ECG encryption and identification based security solution on the Zynq SoC for connected health systems. J. Parallel Distrib. Comput. 2017, 106, 143-152. [CrossRef]

8. Allaert, F.A.; Mazen, N.J.; Legrand, L. The tidal waves of connected health devices with healthcare applications: Consequences on privacy and care management in European healthcare systems. BMC Med. Inform. Decis. Mak. 2017, 17, 10. [CrossRef] [PubMed]

9. Finn, A.; Louviere, J.J. Determining the Appropriate Response to Evidence of Public Concern-The Case of Food Safety. J. Public Policy Mark. 1992, 11, 12-25. [CrossRef]

10. Rose, J.M. Interpreting discrete choice models based on best-worst data: A matter of framing. In Proceedings of the Transportation Research Board 93rd Annual Meeting, Washington, DC, USA, 12-16 January 2014.

11. Skiba, D.J. Connected health 2015: The Year of virtual patient visits. Nurs. Educ. Perspect. 2015, 36, 131-133.

12. Harte, R.P.; Glynn, L.G.; Broderick, B.J.; Rodriguez-Molinero, A.; Baker, P.M.A.; McGuiness, B.; O'Sullivan, L.; Diaz, M.; Quinlan, L.R.; ÓLaighin, G. Human centred design considerations for connected health devices for the older adult. J. Pers. Med. 2014, 4, 245-281. [CrossRef] [PubMed]

13. Darkins, A.; Ryan, P.; Kobb, R.; Foster, L.; Edmonson, E.; Wakefield, B.; Lancaster, A.E. Care coordination/home telehealth: The systematic implementation of health informatics, home telehealth, and disease management to support the care of veteran patients with chronic conditions. Telemed. E-Health 2018, 14, 1118-1126. [CrossRef]

14. Audit Commission UK. Assistive Technology: Independence and Well-Being 4. Available online: http: //webarchive.nationalarchives.gov.uk/20110601170331/ (accessed on 1 March 2019).

15. O’Neill, S.A.; Nugent, C.D.; Donnelly, M.P.; Mccullagh, P.; Mclaughlin, J. Evaluation of connected health technology. Technol. Health Care 2012, 20, 151-167. [PubMed]

16. Caulfield, B.M.; Donnelly, S.C. What is Connected Health and why will it change your practice? QJM Mon. J. Assoc. Phys. 2013, 106, 703-707. [CrossRef] [PubMed]

17. Hussain, M.; Ajmal, M.M.; Gunasekaran, A.; Khan, M. Exploration of social sustainability in healthcare supply chain. J. Clean. Prod. 2018, 203, 977-989. [CrossRef]

18. Tornatzky, L.G.; Fleischer, M.; Chakrabarti, A.K. The Processes of Technological Innovation, 1st ed.; Lexington Books: Lanham, MD, USA; Lexington, MA, USA, 1990.

19. Harte, R.; Quinlan, L.R.; Glynn, L. A Multi-Stage Human Factors and Comfort Assessment of Instrumented Insoles Designed for Use in a Connected Health Infrastructure. J. Pers. Med. 2015, 5, 487-508. [CrossRef] [PubMed]

20. Van Netten, J.J.; Jannink, M.J.A.; Hijmans, J.M.; Geertzen, J.H.B.; Postema, K. Use and usability of custom-made orthopaedic shoes. J. Rehabil. Res. Dev. 2010, 47, 73-81. [CrossRef] [PubMed]

21. Van Netten, J.J.; Jannink, M.J.; Hijmans, J.M.; Geertzen, J.H.; Postema, K. Long-term use of custom-made orthopedic shoes: 1.5-year follow-up study. J. Rehabil. Res. Dev. 2010, 47, 643-649. [CrossRef] [PubMed]

22. Burch, S.; Gray, D.; Sharp, J. Healthcare Financial Management. J. Healthc. Financ. Manag. Assoc. 2008, $71,46-49$.

23. Santos, D.F.S.; Almeida, H.O.; Perkusich, A. A personal connected health system for the Internet of Things based on the Constrained Application Protocol. Comput. Electr. Eng. 2015, 44, 122-136. [CrossRef]

24. Katz, J.E.; Rice, R.E. Public views of mobile medical devices and services: A US national survey of consumer sentiments towards RFID healthcare technology. Int. J. Med. Inform. 2015, 78, 104-114. [CrossRef]

25. Karwatzki, S.; Dytynko, O.; Trenz, M. Beyond the Personalization-Privacy Paradox: Privacy Valuation, Transparency Features, and Service Personalization. J. Manag. Inf. Syst. 2017, 34, 369-400. [CrossRef]

26. Tankard, C. The security issues of the Internet of things. Comput. Fraud Secur. 2015, 9, 11-14. [CrossRef]

27. Kvedar, J.C.; Herzlinger, R.; Holt, M.; Sanders, J.H. Connected health as a lever for healthcare reform: Dialogue with featured speakers from the 5th Annual Connected Health Symposium. Telemed. J. E-Health 2009, 15, 312-319. [CrossRef] [PubMed]

28. Buysse, H.E.; Coorevits, P.; Van Maele, G.; Hutse, A.; Kaufman, J.; Ruige, J.; De Moor, G.J. Introducing telemonitoring for diabetic patients: Development of a telemonitoring 'Health Effect and Readiness' Questionnaire. Int. J. Med. Inform. 2010, 79, 576-584. [CrossRef] [PubMed]

29. Loureiro, M.L.; Dominguez Arcos, F. Applying Best-Worst Scaling in a stated preference analysis of forest management programs. J. For. Econ. 2012, 18, 381-394. [CrossRef] 
30. Cohen, E. Applying Best-Worst Scaling to Wine Marketing. Int. J. Wine Bus. Res. 2009, 21, 8-23. [CrossRef]

31. Zhang, H.; Wang, G.H.; Zheng, W.F. Research on Customer Segmentation of Mobile Payment Based on Maxdiff and Latent Class Analysis. J. Appl. Stat. Manag. 2017, 36, 506-517.

32. Arsham, A.; Gilles, P. Correlates of Multiple Chronic Disease Behavioral Risk Factors in Canadian Children and Adolescents. Am. J. Epidemiol. 2009, 170, 1279-1289.

33. Handcock, M.S.; Gile, K.I. Comment: On the Concept of Snowball Sampling. Sociol. Methodol. 2001, 41, 367-371. [CrossRef]

34. Jia, L.; Xue, G.; Fu, Y.; Xu, L. Factors Affecting Consumers' Acceptance of E-commerce Consumer Credit Service. Int. J. Inf. Manag. 2018, 40, 103-110. [CrossRef]

35. Corbin, J.; Strauss, A. Basics of Qualitative Research: Techniques and Procedures for Developing Grounded Theory, 3rd ed.; Sage Publications: Thousand Oaks, CA, USA, 2008.

36. Glaser, B.; Strauss, A. The Discovery of Grounded Theory: Strategies for Qualitative Research; Aldine: Chicago, IL, USA, 1967.

37. Urquhart, C.; Lehmann, H.; Myers, M.D. Putting the 'theory' back into grounded theory: Guidelines for grounded theory studies in information systems. Inf. Syst. J. 2010, 20, 357-381. [CrossRef]

38. Urquhart, C.; Fernandez, W. Using grounded theory method in information systems: The researcher as blank slate and other myths. J. Inf. Technol. 2013, 28, 224-236. [CrossRef]

39. Eisenhardt, K.M. Building theories from case study research. Acad. Manag. Rev. 1989, 14, 532-550. [CrossRef]

40. Strauss, A.; Corbin, J. Basics of Qualitative Research; Sage: Thousand Oaks, CA, USA, 1990.

41. Dey, I. Grounding Grounded Theory: Guidelines for Qualitative Inquiry; Academic Press: San Diego, CA, USA, 1999.

42. Boyatzis, R.E. The Computer Manager: A Model for Effective Performance; Wiley: New York, NY, USA, 1982.

43. Louviere, J.; Lings, I.; Islam, T.; Gudergan, S.; Flynn, T. An introduction to the application of (case 1) best-worst scaling in marketing research. Int. J. Res. Mark. 2013, 30, 292-303. [CrossRef]

44. Carugati, A.; Fernández, W.; Mola, L.; Rossignoli, C. My choice, your problem? Mandating it use in large organisational networks. Inf. Syst. J. 2018, 28, 6-47. [CrossRef]

(C) 2019 by the authors. Licensee MDPI, Basel, Switzerland. This article is an open access article distributed under the terms and conditions of the Creative Commons Attribution (CC BY) license (http://creativecommons.org/licenses/by/4.0/). 